\title{
Scientific Research and Industrial Development
}

$I^{\mathrm{T}}$ $T$ is difficult if not impossible to appreciate the potentialities of science in industry or in society, or to assess accurately any plan which science can offer us, apart from the consideration of the relations between science and industry which have developed in the past and as they exist to-day. Nor is this a simple task of history. It is immensely complicated by the dynamic character of both science and industry. Society itself does not change its aspects more completely or rapidly than science or industry under the impact of science. For this reason prediction as to the results of planning industry or society on scientific lines is extremely rash. All that can be said is that the scientific method offers a reasonable chance of arriving at an unprejudiced solution of many of our problems and that its technique is sufficiently elastic to be adapted to the solution of new problems as they arise.

The most rapid review of the relations between industry and science during the last century provides convincing evidence of the power of science to assist in the development of industry and the amelioration of society. Of this there are few more striking examples to be found than in the field of fuel economy. A century ago Great Britain was passing through a depression fully comparable with that of the past two years and probably involving even more acute distress. The outlook in the coal and iron industries was gloomy in the extreme, yet at that very time the researches of Michael Faraday on electromagnetic induction were preparing the way for the immense development of the electrical engineering industries with their many branches to-day. The scientific discovery of the production of electric current by mechanical rotation in a magnetic field is the germ from which the dynamo and through it all the numerous branches of electrical power and electric light have sprung. Simultaneously, the engineer was applying his science to the development of railway transport and the advantages of gas lighting were slowly spreading over the country from London and the larger cities.

All these developments themselves induced large demands for coal and iron and finally steel, but as Prof. W. A. Bone pointed out in a recent brilliant lecture, it was the continuous application of scientific methods in the utilisation of fuel that made for progress. James B. Neilson's invention of the hot blast in iron smelting, Whitwell's development of the regenerative principle in blast furnaces, Bessemer's and Thomas and Gilchrist's discoveries in steel making, the Siemens gas-fired open hearth regenerative furnaces - these were all advances in economic production based upon the application of scientific principles to the daily problems of industry, and often upon a scientific study of fundamental laws of heat exchange economy or the complex chemical reactions occurring in the furnace, such as Lowthian Bell carried out for blast furnaces. The gas and coke industries show a con- tinuous record of expansion which is inextricably linked with scientific method and discovery; the Bunsen burner, the Welsbach incandescent mantle, incandescent surface combustion, are all examples of independent scientific discoveries the utilisation of which has profoundly affected the development of the industry.

Similarly in power production the scientific work of Carnot, the experimental researches of Joule, the thermodynamic work of Clausius, Rankine, and Thomson led to the evolution of a scientific theory of the steam engine on which later developments were based. Sir Charles Parsons' invention and development of the steam turbine, perhaps the greatest mechanical achievement of the century, cannot be separated from scientific method and its application to industrial problems. The internal efficiency of the turbine itself has since been in. creased by the scientific study of nozzles, 'bleeding' and the use of higher velocity ratios, while other scientific work with higher boiler pressures, higher vacuum in the condenser, superheating, regenerative ' cascade' fuel-heating, etc., has increased the thermodynamical efficiency of the cycle. Nor have these achievements exhausted the possibilities. It is probable that the opportunities for pioneering in this field for the next generation are as great as ever; much yet remains to be done, particularly in extending scientific control in the utilisation of fuel, which incidentally lies at the root of the smoke abatement problem.

In spite, however, of the convincing demonstration in the past of the power of scientific investigation to alleviate the difficulties of the coal and fuel industries, a hiatus between knowledge and action persists which adds considerably to the difficulties in which the coal industry finds itself to-day. Not even the growing seriousness of atmospheric pollution or the intensity of the unemployment situation has driven Parliament to consider co-ordination in the utilisation of our coal resources in the form of smokeless fuel or oil fuel as a possible economic policy worthy of development. The fuel problem and the competition between raw coal, gas, and electricity is still allowed to develop along haphazard lines, without any attempt to plan and enact a scientific and economic national policy. To this position no contrast could be more startling than the discussion on fuel subjects at the jubilee meetings last year of the Society of Chemical Industry, which was planned to elucidate definite answers to such questions as the probable effect upon the amount of coal raised of the increasing use of oil, of the future development of the gas and electrical industries, of a large development of lowtemperature carbonisation, or of a general improvement of the standard of living.

Only upon the considered answers to such questions can an adequate fuel policy be based, yet here again it is science and industry and not Parliament which is conducting the inquiry. The conference indeed took a sombre view of the prospects 
of any increased demand for coal, Dr. Lessing considering that a decrease in consumption is more probable; and even in the development of the hydrogenation process, prospects of an increased output of raw coal are not bright. Although international agreements might secure more lucrative prices, they are unlikely to affect the tonnage of coal raised. Lieut.-Commander Kenworthy's suggestion that scientific workers, economists, and business men should set up a representative body to examine the economic side of the coal problem was itself a confession that Parliament is not the instrument which will put the coal-mining industry on its feet. Essentially the plea was an admission that the fuel problem demands scientific treatment as an organic unit by the best brains of the country, unfettered by political ties.

In closely related industries the same story of the fundamental dependence of industrial progress upon scientific research is told. Long and patient investigations led Ludwig Mond to the discovery of nickel carbonyl, and the remarkable progress in the metallurgical industries during the last two decades is also based on purely scientific investigations-metals such as tungsten, molybdenum, vanadium being little more than curiosities when they were discovered. The 'Silal' heat-resisting alloys developed by the Cast Iron Research Association are finding a number of successful uses in industry, and it is claimed that the application of the knowledge of moulding sands and refractories acquired as a result of the Association's investigations re. presents an estimated saving to the industry of about $\mathfrak{£} 100,000$ a year. Important advances in our knowledge of aluminium castings have come from the investigations of the Non-Ferrous Metals Research Association, while the investigations carried out by the British Refractories Research Association to improve the durability of refractories react on developments in the ceramic, the iron and steel, and other industries concerned with high temperature operations.

Much has been written in recent years on the dependence of the dyestuffs industry on scientific research and on the part which neglect of scientific research and development played in the decay of the British industry in the latter part of last century. It is, however, by no means generally realised that it was the rapid development of theoretical organic chemistry through the successive ideas of Berzelius, Gerhardt and Laurent, Liebig and Wohler, Dumas, unified by Cannizzaro, Williamson and Kekulé, which laid the foundations upon which the immense edifice of modern organic chemistry is based. Only in the order thus established could the significance of the fundamental discoveries, such as Perkin's mauve, the first azo dye of Peter Griess, Bayer's phthaleins and synthetic indigo, be appreciated and the development of dyestuffs, synthetic drugs, and other branches of chemical industry become possible.

These industries thus owe a double debt to science. Not only were these developments contingent on chemical science opening up the field and establishing some sort of order among the immensely complicated compounds of carbon, but also the fundamental discoveries leading to definite technical advances have frequently been made, often fortuitously, in scientific laboratories.

The renaissance of the British dyestuffs industry under the operation of the Dyestuffs (Import Regulation) Act is in itself a striking example of industrial development through the continuous in tensive application of scientific research. Not content merely to tread in the footsteps of its foreign competitors, in ' caledon jade green', the 'duranol' colours for acetate rayon and the 'soledon' colours, the British industry has been responsible for three out of the five major discoveries in the chemistry of dyes in post-War years.

Moreover, it is interesting to note that, so far from the field being exhausted or its potentialities limited by the discoveries and developments of last century, although the main structure of organic chemistry has remained essentially unchanged during the last three decades, within that period the view that chemistry is a static science has been confounded by discoveries and industries in almost every branch of organic chemistry. The technical production of indigo essentially dates from the Deutscher Golstand Silberscheide-anstalt or Roessler sodamide fusion patent of 1901, the Sandmeyer process from indigo being still more recent. The oldest section of the dyestuffs field, the triphenylmethane or aniline colours formerly regarded as comparatively fugitive, was found in 1915 to be capable of yielding with phosphotungstic acid a series of lake or pigment colours of surprising fastness to light, whilst the azo section is still providing new dyes for overcoming the dyeing difficulties presented by the new synthetic fibres.

Closely parallel with the development of the dyestuffs industry is that of synthetic drugs and fine chemicals. Here again the industry may be traced back to much purely scientific work such as Kolbe's synthesis of salicylic acid, and its expansion has invariably been connected with external scientific work, like Knorr's discovery of antipyrine, Ehrlich's salvarsan, Fourneau's 309, Kraut's aspirin, Molle and Kleist's veronal, the isolation and synthesis of adrenaline, Banting and Best's isolation of insulin, Kendall's preparation of thyroxin and its brilliant synthesis by Harington. Pasteur's scientific investigations on yeast were prompted by a brewing difficulty and led him to the discovery of the whole theory of fermentation, the existence and action of bacteria, thence to the pasteurisation process, and finally to the discovery of the antitoxin of hydrophobia. These discoveries have not merely transformed the brewing, yeast, dairy, and cheese industries, but also have led to the rise of important new branches in the production by fermentation of solvents such as acetone and butyl alcohol. It would be difficult to measure the debt of either the fermentation industries or, indeed, of humanity to the scientific work of Pasteur.

Even in the older industries, scientific research has been responsible for revolutionary changes and developments. The art of soap-making has been

No. 3277 , Vor. 130] 
transformed into a science. Sabatier's observation of the hydrogenating properties of finely divided nickel is the germ from which has developed the industrial hydrogenation or hardening of oils and fats and innumerable processes in almost every section of organic chemistry, including the Berginisation process for obtaining liquid fuels from coal. Scientific investigations on nitrocellulose and cellulose acetate and their solvents have led to the discovery of lacquers which have not only revolutionised the paint and varnish industry, but also made possible the enormous expansion of the automobile industry. The leather substitute used extensively in upholstering motor cars has itself been produced as an outcome of the scientific investigation of nitrated cellulose. Equally important is the development of the whole rayon industry from scientific investigations and observations in the same field of cellulose-Chardonnet's discovery of nitrocellulose silk and Cross and Bevan's viscose. The technical possibilities of any one of these discoveries were scarcely dreamed of by industry when the first investigation was commenced. Finally, the great fertiliser industry, including the fixation of atmospheric nitrogen, is essentially based on Liebig's discovery of the superphosphate process and Lawes and Gilbert's patient investigations on the effect of fertilisers on plant growth.

The above brief review of the creative influence of science on industry might be extended by reference to the radio industry, which is similarly the outcome of the scientific researches of Clerk Maxwell and Hertz on the properties of the electric waves. The telephone originated with the experiments of Bell, and the cinematograph industry, the automobile, the aircraft, the synthetic ammonia industries, are all the outcome of fundamental investigations, the practical significance of which was undreamt of at the time, and each now gives employment to thousands of workers.

Admittedly, society must look to creative science for the best hope of an ultimate solution of the unemployment situation. Indirectly, therefore, the problem of unemployment is linked with the prob: lem of fostering the most vigorous intellectual activity among scientific workers and attracting into the service of science the most able minds the present generation can provide. Conditions which tend to lower the standard of recruitment for the various branches of the profession of science may react dangerously upon the welfare of the community. If full contact is secured between the finest type of such scientific work and industry, a fertilisation of industrial research will result from which all branches of the community will benefit. So competent an observer as Prof. Henry Clay remarks in this connexion that industrial expansion takes place less as the result of the establishment of entirely new firms to exploit new processes and new demands than as a result of existing firms, which are making profits by the efficiency of their management, applying these profits to finance expansion in new directions. It would seem that only through the rationalisation of industry can creative science exert its full influence in expanding employment.

(To be continued.)

\section{The Structure of Wind over Level Country *}

$\mathrm{A}^{\mathrm{s}}$ BOUT seven years ago, in connexion with the A construction and navigation of airships, the Meteorological Office was called upon to conduct further investigations into certain problems of wind structure. The work was taken up with energy and ability by M. A. Giblett, the already distinguished young meteorologist who afterwards in 1930 lost his life in the ill-fated $R 101$. The researches on wind structure were completed by members of the meteorological staff of the Rcyal Airship Works at Cardington, and the results are now issued in an impressive volume as Geophysical Memoir No. 54.

The data discussed in this memoir were derived mainly from four anemographs, three of which were set up at the corners of an equilateral triangle of I80 feet side-approximately the length of the airship $R 101$-and a fourth at the middle point of one side of the triangle.

The instruments could be arranged to use recording drums turning at the normal rate, that is, once in 24 hours, or at 12 times the normal rate, or at 144 times the normal rate. A time-marking device could be set to operate simultaneously upon

* Geophysical Memojr No. 54. By the late M. A. Giblett (Superintendent of the Airship Division of the Meteorological Office), and other Members of the Staff of the Office. Pp. 119 and plates $\mathrm{xxi}$ (London: H.M. Stationery Office.) 10s, net. the individual records. The instrumental arrangements were in charge of B. C. V. Oddie ; a complete description of the equipment, together with photographs and a discussion of possible instrumental errors, is given in Part I.

After that, the work falls naturally into two main branches-the facts of observation and the discussion of the observations. Parts II. and IV. contain results dealing respectively with the horizontal fluctuations in wind in time and space and with the variation of wind with height; seven appendices are devoted to the statistics, whilst the work, in all, includes no less than 95 figures, containing, in particular, reproductions of numerous records, ordinary, quick-run, and ultra-quick run. All this is a valuable store of information which probably will afford material for the discussion of further problems. The discussion in this work is contained mainly in Parts III. and V.

In Part III., C. S. Durst outlines an attractive theory of eddies. The gusts, lulls, and changes of direction in an air current are commonly ascribed to more or less circular eddies embedded in the general flow, but in the study of the ultra-quick runs it has been noted that " the wind velocity does not change regularly backwards and forwards between gusts and lulls, but that the velocity rises 